\title{
Development of a new semi-analytical model for cross-borehole flow experiments in fractured media
}

\author{
Delphine Roubinet ${ }^{1}$, James Irving ${ }^{2}$, and Frederick D. Day-Lewis ${ }^{3}$
}

\begin{abstract}
Analysis of borehole flow logs is a valuable technique for identifying the presence of fractures in the subsurface and estimating properties such as fracture connectivity, transmissivity and storativity. However, such estimation requires the development of analytical and/or numerical modeling tools that are well adapted to the complexity of the problem. In this paper, we present a new semi-analytical formulation for cross-borehole flow in fractured media that links transient vertical-flow velocities measured in one or a series of observation wells during hydraulic forcing to the transmissivity and storativity of the fractures intersected by these wells. In comparison with existing models, our approach presents major improvements in terms of computational expense and potential adaptation to a variety of fracture and experimental configurations. After derivation of the formulation, we demonstrate its application in the context of sensitivity analysis for a relatively simple two-fracture synthetic problem, as well as for field-data analysis to investigate fracture connectivity and estimate fracture hydraulic properties. These applications provide important insights regarding (i) the strong

\footnotetext{
${ }^{1}$ Corresponding author: Applied and Environmental Geophysics Group, University of Lausanne, Switzerland; delphine.roubinet@unil.ch

${ }^{2}$ Applied and Environmental Geophysics Group, University of Lausanne, Switzerland

${ }^{3}$ U.S. Geological Survey, Storrs, CT 06269, USA
} 
sensitivity of fracture property estimates to the overall connectivity of the system; and (ii) the non-uniqueness of the corresponding inverse problem for realistic fracture configurations.

Keywords: Fractures and faults, Groundwater, Cross-borehole flow experiment, Semi-analytical model

\section{1. Introduction}

2 The study of fractured rocks is highly important in a wide variety of re3 search fields and applications including hydrogeology, geothermal energy,

4 hydrocarbon extraction, and the long-term storage of toxic waste (Carneiro,

5 2009; Dershowitz and Miller, 1995; Gautam and Mohanty, 2004; Kolditz and 6 Clauser, 1998; Rotter et al., 2008). As fractures represent either rapid ac7 cess to some resource of interest or potential pathways for the migration of 8 contaminants in the subsurface, identifying their presence and determining 9 their properties are critical, albeit highly challenging, tasks. In order to tackle these challenges, numerous fracture characterization methods have 11 been developed; borehole geophysical logging (e.g., (Hearst et al., 2000; 12 Keys and MacCary, 1971)), dilution tests (e.g., (Paillet, 2012)), single and 13 cross-borehole flow experiments (e.g., (Day-Lewis et al., 2011; Le Borgne 14 et al., 2006; Paillet et al., 2012)), as well as temperature measurements 15 (e.g., (Klepikova et al., 2014; Leaf et al., 2012; Pehme et al., 2013)) have 16 all been used in an effort to gain both qualitative and quantitative informa17 tion regarding the properties of individual fractures and fracture networks. ture connections and hydraulic properties from vertical-flow-velocity measurements conducted in one or more observation boreholes under forced hydraulic conditions. Previous studies have demonstrated that analysis of 
these data, especially when acquired in a transient manner, can provide important information on fracture connectivity, transmissivity, and storativity, with significantly less effort and expense than conventional packer tests (Le Borgne et al., 2006; Paillet, 1998; Paillet et al., 2012; Williams and Paillet, 2002). As such, cross-borehole flow data can yield, at the very least, key preliminary information on highly conductive fractures and/or fracture zones that may be subsequently targeted for more detailed and costly investigations.

Because of the strong non-linearity and non-uniqueness of the problem, relating vertical-flow velocities measured in a borehole to fracture hydraulic characteristics is by no means straightforward and generally requires the use of adapted mathematical models. To this end, analytically-based (DayLewis et al., 2011; Paillet, 1998) and numerical (Klepikova et al., 2013) forward modeling approaches have been utilized for the interpretation of single and cross-borehole flow data. The strong advantage of analytically-based formulations is their low computational cost, which means that they can be effectively used within stochastic inverse approaches, as well as for parameter and predictive uncertainty quantification and detailed sensitivity analysis. Indeed, numerical solutions such as those involving finite elements, albeit highly flexible, are not generally suitable in the context of the hundreds to thousands of forward solutions necessary to address the latter goals.

Existing analytically-based solutions for flow experiments in fractured media are either limited to single-borehole tests (Day-Lewis et al., 2011) or based on a semi-quantitative approach involving a relative description of the hydraulic properties that assumes the same storativity for all the fractures (Le Borgne et al., 2006; Paillet et al., 2012; Williams and Paillet, 2002). Although the latter approach, which is designed for cross-borehole studies, 
49 allows for individual fractures to intersect either the observation borehole, the pumped borehole, or both, its flexibility is limited in terms of the num-

ber of boreholes considered and the interactions between the fractures. In particular, the formulation as presented is limited to a single observation borehole, and its extension to more complex experimental configurations, if feasible, does not seem straightforward.

With the aim of addressing the above limitations, we present in this paper a new semi-analytical model for cross-borehole flow experiments in fractured media. Treating each fracture as a locally-leaky confined aquifer, borehole vertical-flow velocities are calculated by coupling the continuity equations for flow in the aquifers with a set of equations governing flow in the boreholes. Our model is presented in a general manner, with all assumptions fully noted, and it offers the flexibility of modeling a variety of fracture and experimental conditions, for example the presence of multiple observation boreholes and multiple connection configurations. We begin below with a full derivation and description of the developed semi-analytical modeling approach. Next, the approach is demonstrated in the context of sensitivity analysis for a simple two-fracture synthetic problem involving two boreholes and two different connection configurations. Finally, we present the results of estimating fracture connectivity, transmissivity, and storativity from field data collected and previously analyzed by Paillet et al. (2012) using their developed semi-quantitative approach. 


\section{Model development}

\subsection{Overall approach}

We consider in this paper a general cross-borehole flow experiment whereby hydraulic forcing (i.e., pumping or injection) is conducted in one borehole and transient vertical-flow-velocity measurements are acquired at different depths in one or more observation boreholes, the latter of which are usually different from the pumped borehole. Measurements of the flow velocity are considered to be available between each fracture intersecting the observation borehole(s), as well as between the most shallow fracture(s) and the surface. Depending on the connectivity of the system, the fractures in the observation borehole(s) may or may not intersect the pumped/injection borehole. As an example, Figure 1a shows a schematic representation of a fractured environment where the fracture located at position $z=26 \mathrm{~m}$ in the observation borehole intersects only this borehole. The fracture located at position $z=52 \mathrm{~m}$, on the other hand, intersects both the observation and pumped boreholes.

To model the general configuration described above, we represent the fractures as a series of equivalent confined aquifers that are hydraulically connected through the boreholes (e.g., Paillet, 1998; Paillet et al., 2012; Williams and Paillet, 2002). Figure 1b shows the equivalent representation of the system in Figure 1a involving five confined aquifers and two boreholes. The vertical-flow velocities occurring in each borehole under forced hydraulic conditions are denoted by $q_{I}^{i}$, where $i$ is the borehole number and $I$ is the aquifer number above which the vertical flow occurs. The hydraulic properties of aquifer $I$ are its transmissivity $T_{I}$ and storativity $S_{I}$. Note that lower- and upper-case indices are used below to indicate borehole and 
aquifer numbering, respectively.

Development of our model for cross-borehole flow involves coupling of the continuity equations for flow in the confined aquifers with equations governing the vertical flows between the aquifers through the boreholes. The latter flows are taken into account as localized source/sink terms and their average velocities are related to hydraulic head differences in the boreholes through the Hagen-Poiseuille law. It should be noted that similar coupling methods have been used for the evaluation of fluid leakage through abandoned wells in multilayered-aquifer systems (Avci, 1994; Cihan et al., 2011; Nordbotten et al., 2004). In these studies, the final solution is expressed in terms of the hydraulic head and formulated in either the time or Laplace domains, and both the pumping and observation boreholes are assumed to intersect the series of parallel aquifers. In comparison, our formulation is especially developed for cross-borehole experiments in fractured media in that: (i) it allows for situations where a fracture intersects only some of the boreholes; (ii) the final solution is expressed directly in terms of the relative borehole vertical-flow velocities and solved in the time domain.

In the following, we first develop an analytical expression for the hydraulic head in a single confined aquifer subject to one or more localized leakages (Section 2.2). This leads us to develop an expression for the borehole vertical-flow velocities for a system of confined aquifers where the localized leakages correspond to the borehole connections (Section 2.3). Lastly, details are provided on the semi-analytical implementation of the latter expression in order to determine vertical-flow velocities from a given set of aquifer properties and connections. This is done through the solution of a linear system (Appendix). 


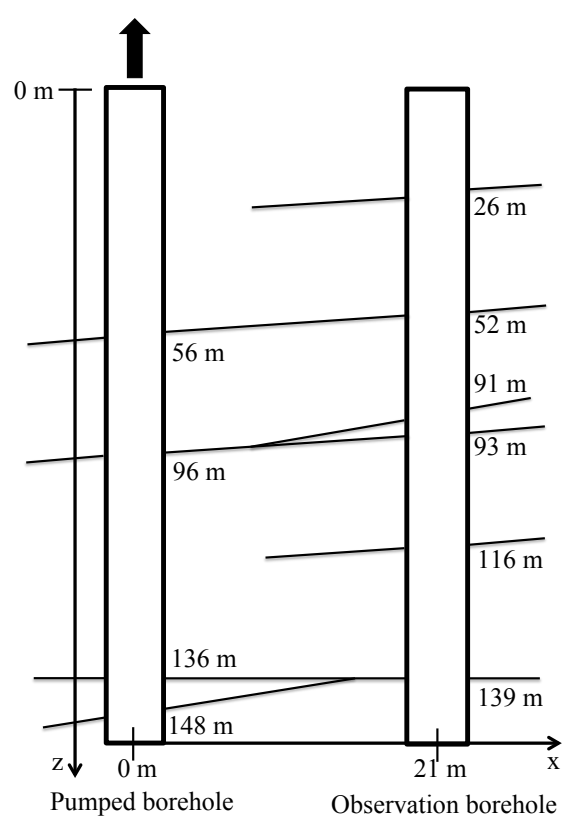

(a)

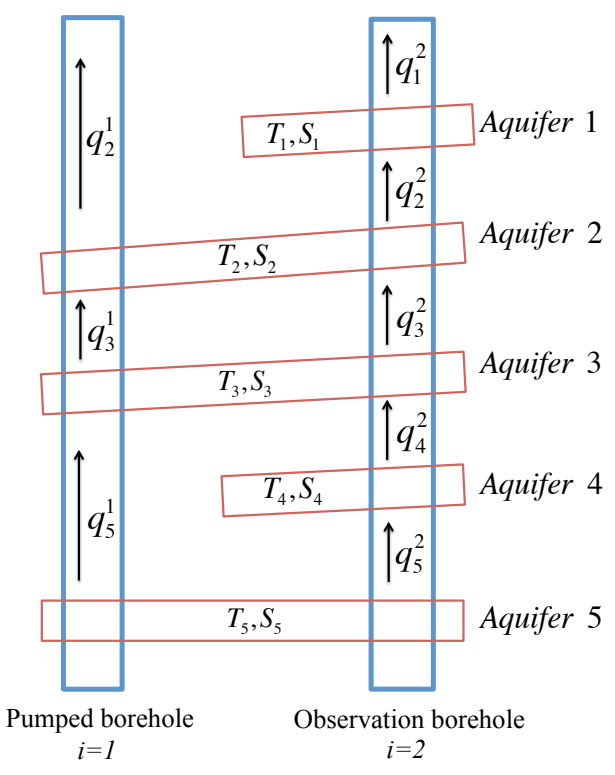

(b)

Figure 1: (a) Schematic illustration of the fractured geological formation considered in Paillet et al. (2012); (b) Equivalent representation as a series of confined aquifers connected through the boreholes. Vertical-flow velocities measured above aquifer $I$ in borehole $i$ are denoted by $q_{I}^{i}$, whereas aquifer transmissivities and storativities are denoted by $T_{I}$ and $S_{I}$, respectively.

\subsection{Hydraulic head in a single, locally-leaky, confined aquifer}

\subsubsection{Mathematical formulation}

Consider a homogeneous, isotropic, confined aquifer where flow can be represented as two-dimensional in the $x-y$ plane. The hydraulic head distribution averaged over the aquifer thickness, $h(x, y, t)[\mathrm{m}]$ at position $(x, y)$ and time $t$, is governed by the following continuity equation for flow in a 
confined aquifer (e.g., Bear, 1979):

$$
S \frac{\partial h}{\partial t}-T\left(\frac{\partial^{2} h}{\partial x^{2}}+\frac{\partial^{2} h}{\partial y^{2}}\right)=q,
$$

where $T\left[\mathrm{~m}^{2} / \mathrm{s}\right]$ and $S[-]$ are the aquifer transmissivity and storativity, respectively, and $q(x, y, t)[\mathrm{m} / \mathrm{s}]$ represents the spatial and temporal distribution of sources $(q>0)$ and sinks $(q<0)$, which are defined as flows per unit area per unit time. Let us also consider that the time dependence of the hydraulic head is caused by a pumping or injection experiment that begins at time $t=0$ in a domain where the initial hydraulic head distribution $h_{0}(x, y)$ is governed by the steady-state equation

$$
-T\left(\frac{\partial^{2} h_{0}}{\partial x^{2}}+\frac{\partial^{2} h_{0}}{\partial y^{2}}\right)=q_{0}
$$

where $q_{0}(x, y)$ is the spatial distribution of sources and sinks existing before the beginning of the experiment (i.e., for $t<0$ ). Note that this implies a boundary condition of $h(x, y, t)=h_{0}(x, y)$ at infinite positions, where no effect of the pumping/injection experiment is to be expected.

Considering equations (1) and (2), the relative hydraulic head or drawdown in the aquifer $H(x, y, t)=h(x, y, t)-h_{0}(x, y)$ is governed by the equation

$$
\frac{\partial H}{\partial t}-\alpha\left(\frac{\partial^{2} H}{\partial x^{2}}+\frac{\partial^{2} H}{\partial y^{2}}\right)=\frac{Q}{S}
$$

and subject to the initial condition $H=0$ and boundary condition $H=0$ at infinite positions. Here, $Q(x, y, t)=q(x, y, t)-q_{0}(x, y)$ represents a relative source/sink term and $\alpha=T / S$ is the hydraulic diffusivity. Note that the definition of $Q$ in this manner is critical as interpretations of cross-borehole flow experiments are based on relative flow-velocity measurements.

The elementary solution (or Green's function) $H^{*}$ corresponding to equation (3) can be obtained by replacing the right-hand side of the expression 
with the Dirac delta function $\delta\left(x-x^{\prime}, y-y^{\prime}, t-t^{\prime}\right)$ and considering the initial and boundary conditions. This yields

$$
H^{*}\left(x-x^{\prime}, y-y^{\prime}, t-t^{\prime}\right)=\frac{e^{-\frac{\left(x-x^{\prime}\right)^{2}+\left(y-y^{\prime}\right)^{2}}{4 \alpha\left(t-t^{\prime}\right)}}}{4 \pi \alpha\left(t-t^{\prime}\right)} u\left(t-t^{\prime}\right),
$$

where $u(\cdot)$ is the Heaviside step function. $H^{*}\left(x-x^{\prime}, y-y^{\prime}, t-t^{\prime}\right)$ can be interpreted as the hydraulic head at position $(x, y)$ and time $t$ due to an instantaneous injection at position $\left(x^{\prime}, y^{\prime}\right)$ and time $t^{\prime}$. As is standard practice (e.g., Carslaw and Jaeger (1986)), this result can be multiplied with equation (3) and integrated over space and time to express the general solution to equation (3) as

$$
H(x, y, t)=\frac{1}{S} \int_{0}^{t} \int_{-\infty}^{+\infty} \int_{-\infty}^{+\infty} Q\left(x^{\prime}, y^{\prime}, t^{\prime}\right) H^{*} \mathrm{~d} x^{\prime} \mathrm{d} y^{\prime} \mathrm{d} t^{\prime}
$$

which can be rewritten as

$$
H(x, y, t)=\frac{1}{S} \int_{-\infty}^{+\infty} \int_{-\infty}^{+\infty} Q *_{t} H^{*} \mathrm{~d} x^{\prime} \mathrm{d} y^{\prime}
$$

where the convolution product in time is defined as

$$
f *_{t} g=\int_{0}^{t} f\left(t^{\prime}\right) g\left(t-t^{\prime}\right) \mathrm{d} t^{\prime}
$$

Considering the relative source/sink term in equation (6) as being the result of localized leakages through boreholes intersecting the aquifer, $Q(x, y, t)$ can be approximated as

$$
Q(x, y, t)=\left\{\begin{array}{cll}
Q^{i}(t), & \text { if }(x, y) \in C_{i}, & i=1, \ldots, n \\
0, & \text { if }(x, y) \notin C_{i}, & i=1, \ldots, n
\end{array}\right.
$$

where $Q^{i}(t)$ is the relative average flow velocity over the cross-sectional area $C_{i}$ of borehole $i$, and $n$ is the number of boreholes intersecting the aquifer. 
208 with $r=\sqrt{x^{2}+y^{2}}$.

where $\mathcal{H}^{i}=\mathcal{H}^{i}\left(x, y, t-t^{\prime}\right)$ is defined as

$$
\mathcal{H}^{i}\left(x, y, t-t^{\prime}\right)=\frac{1}{S} \int_{C_{i}} H^{*}\left(x-x^{\prime}, y-y^{\prime}, t-t^{\prime}\right) \mathrm{d} x^{\prime} \mathrm{d} y^{\prime} .
$$

\subsubsection{Relationship to existing analytical solutions}

Consider a single borehole experiment $(n=1)$ where a constant flow rate of $\mathcal{Q}\left[\mathrm{m}^{3} / \mathrm{s}\right]$ is injected into $(\mathcal{Q}>0)$ or extracted from $(\mathcal{Q}<0)$ a single confined aquifer. The borehole has cross-sectional area $C_{1}$, radius $r_{1}$, and is located at position $\left(x_{1}, y_{1}\right)=(0,0)$. The relative hydraulic head or drawdown in the aquifer can be expressed using equation (9) as

$$
H(x, y, t)=\int_{0}^{t} Q^{1}\left(t^{\prime}\right) \mathcal{H}^{1}\left(x, y, t-t^{\prime}\right) \mathrm{d} t^{\prime},
$$

where $\mathcal{H}^{1}\left(x, y, t-t^{\prime}\right)$, defined in equation (10), can be approximated here as

$$
\mathcal{H}^{1}\left(x, y, t-t^{\prime}\right)=\frac{\pi r_{1}^{2}}{S} H^{*}\left(x-x_{1}, y-y_{1}, t-t^{\prime}\right) .
$$

Assuming an absence of vertical flow in the borehole before the beginning of the experiment, the relative average flow velocity $Q^{1}$ is related to the constant flow rate $\mathcal{Q}$ through $Q^{1}=\mathcal{Q} /\left(\pi r_{1}^{2}\right)$, which leads to the expression

$$
H(x, y, t)=\frac{\mathcal{Q}}{S} \int_{0}^{t} \frac{e^{-\frac{x^{2}+y^{2}}{4 \alpha\left(t-t^{\prime}\right)}}}{4 \pi \alpha\left(t-t^{\prime}\right)} u\left(t-t^{\prime}\right) \mathrm{d} t^{\prime} .
$$

The above equation can be rewritten as the well-known Theis solution

$$
H(x, y, t)=\frac{\mathcal{Q}}{4 \pi T} \int_{0}^{t} \frac{e^{-\frac{r^{2} S}{4 T \tau}}}{\tau} u(\tau) \mathrm{d} \tau,
$$




\subsection{Accounting for borehole connections between aquifers}

\subsubsection{Hydraulic head in a connected aquifer}

Consider now a scenario involving multiple aquifers where aquifer number $I$ is intersected by $n_{I}$ boreholes. Each of these boreholes $i\left(i=1, \ldots, n_{I}\right)$ passes through a sequence of aquifers, which we denote by the ordered set $A^{i}$. As an example, for the equivalent representation illustrated in Figure $1 \mathrm{~b}, A^{1}=$ $\{2,3,5\}$ and $A^{2}=\{1,2,3,4,5\}$ for the pumped and observation boreholes, respectively, as the pumped borehole intersects Aquifers 2, 3, and 5 and the observation borehole intersects all of the aquifers in the system. Let us define $A_{-}^{i}(I)$ and $A_{+}^{i}(I)$ as the aquifers that are located above and below aquifer $I$ in borehole $i$, respectively, and thus which correspond to the previous and next aquifers with respect to $I$ in the set $A^{i}$. The definition of $A_{-}^{i}(I)$ and $A_{+}^{i}(I)$ clearly depends on the considered borehole as not all fractures will intersect every well (e.g., in Figure $1 \mathrm{~b}, A_{-}^{1}(3)=2$ and $A_{+}^{1}(3)=5$ whereas $A_{-}^{2}(3)=2$ and $\left.A_{+}^{2}(3)=4\right)$. Aquifers $I, A_{-}^{i}(I)$, and $A_{+}^{i}(I)$ are located at depths $z_{I}^{i}, z_{A_{-}^{i}(I)}$, and $z_{A_{+}^{i}(I)}$, respectively (Figure 2).

Let $h_{I}(x, y, t)$ denote the transient hydraulic head distribution in aquifer $I$, which is governed by equation (1). As illustrated in Figure 2, the borehole connections between this aquifer and aquifers $A_{-}^{i}(I)$ and $A_{+}^{i}(I)$ imply sink and source terms at the borehole locations given by the vertical-flow velocities $q_{I}^{i}$ and $q_{A_{+}^{i}(I)}^{i}$, respectively. Equation (9) thus leads to the following expression:

$$
h_{I}(x, y, t)=h_{0, I}+\sum_{i=1}^{n_{I}}\left[Q_{A_{+}^{i}(I)}^{i}-Q_{I}^{i}\right] *_{t} \mathcal{H}_{I}^{i}
$$

where $h_{0, I}$ is the initial hydraulic head distribution in the aquifer, and $Q_{I}^{i}$ and $Q_{A_{+}^{i}(I)}^{i}$ are the relative flow velocities corresponding to $q_{I}^{i}$ and $q_{A_{+}^{i}(I)}^{i}$, re- 
spectively. Note that $\mathcal{H}_{I}^{i}$ in the above expression is defined by equations (10) and (4) with all hydraulic properties set equal to their values in aquifer $I$.

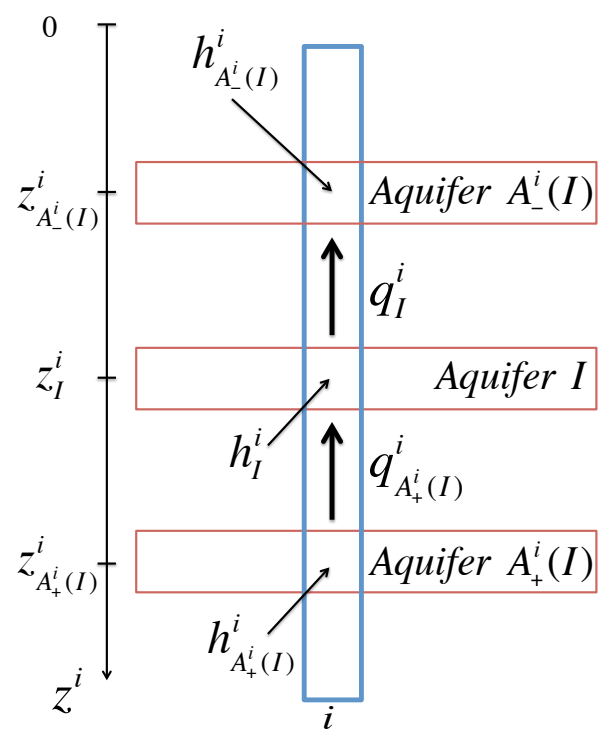

Figure 2: Schematic illustration of an aquifer $I$ connected through borehole $i$ to the aquifers above and below, $A_{-}^{i}(I)$ and $A_{+}^{i}(I)$, respectively. The average vertical-flow velocities above aquifers $I$ and $A_{+}^{i}(I)$ are denoted by $q_{I}^{i}$ and $q_{A_{+}^{i}(I)}^{i}$, respectively.

\subsubsection{Borehole vertical-flow velocities}


(Figure 2) can be expressed as

$$
q_{I}^{i}(t)=\beta_{I}^{i}\left(h_{I}^{i}-h_{I^{\prime}}^{i}\right),
$$

where we have introduced for the sake of notational clarity variable $I^{\prime}=$ $A_{-}^{i}(I)$ denoting the overlying aquifer, and where $h_{I}^{i}$ and $h_{I^{\prime}}^{i}$ are the point hydraulic head values in aquifers $I$ and $I^{\prime}$ at the location of borehole $i$, respectively. Expression (16) has been utilized in previous studies where the term $\beta_{I}^{i}$ is given by $\beta_{I}^{i}=\kappa^{i} / l_{I}^{i}$, with $\kappa^{i}\left[\mathrm{~m} / \mathrm{s}^{-1}\right]$ being the hydraulic conductivity of borehole $i$ and $l_{I}^{i}[\mathrm{~m}]$ the vertical distance between aquifers $I$ and $I^{\prime}$ (Chen and Jiao, 1999; Cihan et al., 2011; Nordbotten et al., 2004). In the present work, we assume that $\beta_{I}^{i}$ can be deduced from the HagenPoiseuille law applied to the hydraulic head, meaning that $\beta_{I}^{i}=\frac{\rho g r_{i}^{2}}{8 \mu l_{I}^{i}}$, where $r_{i}[\mathrm{~m}]$ is the borehole radius, $g$ is $\left[\mathrm{m} \mathrm{s}^{-2}\right]$ the gravitational acceleration, and $\rho\left[\mathrm{g} \mathrm{m}^{-3}\right]$ and $\mu\left[\mathrm{g} \mathrm{m}^{-1} \mathrm{~s}^{-1}\right]$ are the density and dynamic viscosity of water, respectively. Note, however, that expression (16) could be replaced by a different relationship if the assumption of borehole laminar flow is deemed unjustified (Chen and Jiao, 1999).

Equation (15) can be used to express the quantities $h_{I}^{i}$ and $h_{I^{\prime}}^{i}$ as

$$
h_{I}^{i}(t)=h_{0, I}^{i}+\sum_{j=1}^{n_{I}}\left[Q_{A_{+}^{j}(I)}^{j}-Q_{I}^{j}\right] *_{t} \mathcal{H}_{I}^{i, j}
$$

and

$$
h_{I^{\prime}}^{i}(t)=h_{0, I^{\prime}}^{i}+\sum_{j=1}^{n_{I^{\prime}}}\left[Q_{A_{+}^{j}\left(I^{\prime}\right)}^{j}-Q_{I^{\prime}}^{j}\right] *_{t} \mathcal{H}_{I^{\prime}}^{i, j}
$$

where index $j$ is now used to sum over all of the boreholes intersecting the considered aquifer. Variable $\mathcal{H}_{K}^{i, j}$ in the above expressions is defined by equation (10) with $\mathcal{H}_{K}^{i, j}=\mathcal{H}_{K}^{j}\left(x_{i}, y_{i}, t-t^{\prime}\right)$, where $\left(x_{i}, y_{i}\right)$ is the position of 
borehole $i$. Combining expressions (16), (17) and (18) leads to the following expression for the relative flow velocity $Q_{I}^{i}$ :

$$
\begin{aligned}
Q_{I}^{i}(t)= & \beta_{I}^{i} \sum_{j=1}^{n_{I}}\left[Q_{A_{+}^{j}(I)}^{j}-Q_{I}^{j}\right] *_{t} \mathcal{H}_{I}^{i, j} \\
& -\beta_{I}^{i} \sum_{j=1}^{n_{I^{\prime}}}\left[Q_{A_{+}^{j}\left(I^{\prime}\right)}^{j}-Q_{I^{\prime}}^{j}\right] *_{t} \mathcal{H}_{I^{\prime}}^{i, j}
\end{aligned}
$$

At the top of an observation well (e.g., flow velocity $q_{1}^{2}$ in Figure 1b), expression (16) cannot be used as it relies upon having an expression for the hydraulic head at the intersection of the well and an overlying fracture. In this case, the vertical flow occurring in the borehole is only due to wellbore storage and the flow velocity can be expressed as (Lapcevic et al., 1993)

$$
q_{I}^{i}(t)=\frac{\partial h_{I}^{i}}{\partial t}
$$

Assuming steady-state equilibrium as the initial condition at the start of the cross-borehole experiment, the initial flow velocity at the top of the boreholes is zero and thus the relative flow velocity $Q_{I}^{i}$ is equal to $q_{I}^{i}$. Expression (20) can then be combined with the hydraulic head expression (17), which leads to:

$$
Q_{I}^{i}(t)=\sum_{j=1}^{n_{I}}\left[\partial_{t} Q_{A_{+}^{j}(I)}^{j}-\partial_{t} Q_{I}^{j}\right] *_{t} \mathcal{H}_{I}^{i, j}
$$

where $\partial_{t}$ denotes the time derivative. At the top of the pumped borehole, the relative flow velocity is simply equal to $\mathcal{Q} /\left(\pi r_{1}^{2}\right)$ where $\mathcal{Q}$ is the pumped flow rate and $r_{1}$ is the borehole radius.

Equations (19) and (21) provide expressions for the transient relative vertical-flow velocities above the fractures in each borehole as a linear function of the other flow velocities. As such, the relative flow velocities can 
be determined by solving the linear system $\mathbf{A x}=\mathbf{b}$, where vector $\mathbf{x}$ contains the flow velocities discretized in time and matrix $\mathbf{A}$ depends upon the fracture hydraulic properties, connectivity, and experimental geometry. Full details on the formulation of this linear system and its semi-analytical implementation are provided in the Appendix. It is important to emphasize that, despite the fact that equations (19) and (21) are linear with respect to the relative flow velocities, the inverse problem involving the estimation of aquifer hydraulic properties from cross-borehole vertical-flow measurements is highly non-linear because the hydraulic parameters of interest are contained in matrix $\mathbf{A}$ and not in vector $\mathbf{x}$.

\section{Results and applications}

\subsection{Synthetic study}

\subsubsection{Experimental configurations}

As a first example of the application of the modeling methodology for crossborehole flow presented in Section 2, we consider two simple synthetic configurations involving two fractures and a single observation borehole. In the first configuration (Figure 3a), the pumped and observation boreholes intersect both fractures. In the second configuration (Figure $3 \mathrm{~b}$ ), the observation borehole intersects both fractures but the pumped borehole is connected to only the first (upper) fracture. The upper and lower fractures are represented in the model as confined aquifers having transmissivities $T_{1}$ and $T_{2}$ and storativities $S_{1}$ and $S_{2}$, respectively. They are horizontal and located at depths of 10 and $20 \mathrm{~m}$ for both configurations. The radius of the pumped and observation wells is $3.75 \mathrm{~cm}$ and the distance between them is $20 \mathrm{~m}$. Hydraulic forcing of the system is conducted by extracting water at a rate of 


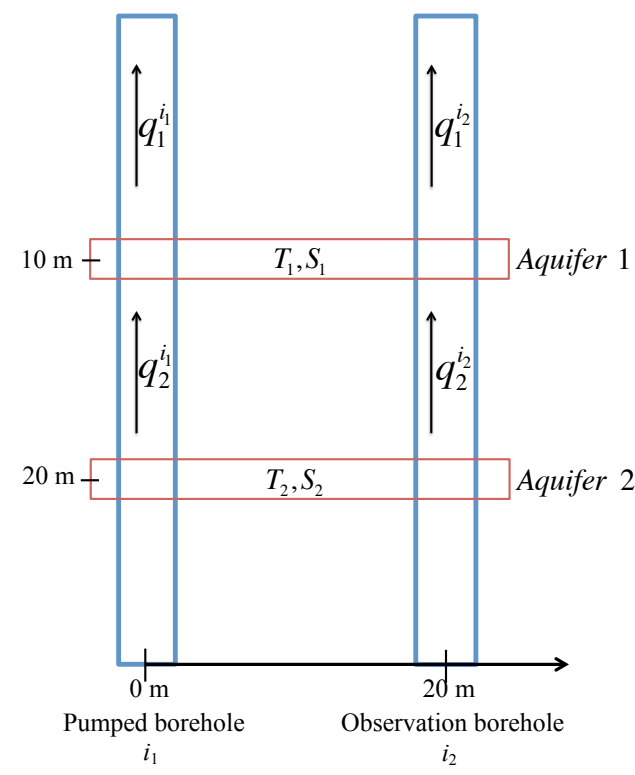

(a) Configuration with connection

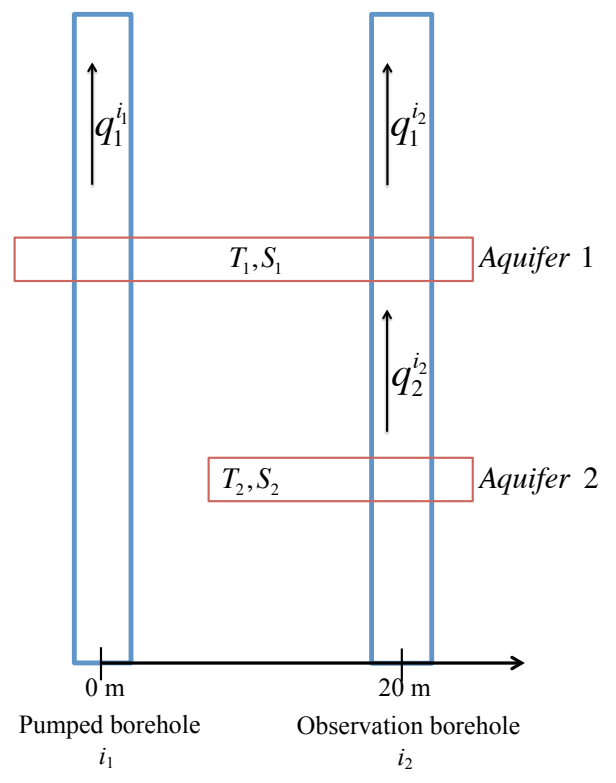

(b) Configuration without connection

Figure 3: Two experimental configurations considered in our synthetic study, where the fractures have been represented as confined aquifers.

$8 \mathrm{~L} / \mathrm{min}$ for 20 minutes at the top of the open pumped borehole. An absence of vertical flow is assumed before the beginning of the pumping experiment (i.e., no ambient flow for $t<0$ ), and flow measurements are assumed to be available over the course of pumping as well as for an additional 20 minutes after pumping is stopped.

Figure 4 shows the transient vertical flows in the observation borehole calculated using our model for the two configurations presented in Figure 3 and for fracture transmissivity values of $T_{1}=T_{2}=10^{-5} \mathrm{~m}^{2} / \mathrm{s}$ and storativity values of $S_{1}=S_{2}=10^{-5}$. Flow velocities (m/s) were converted into flow rates $(\mathrm{L} / \mathrm{min})$ for the figure. We observe that the vertical flow occurring above Aquifer 1 is identical for the configurations with and without connec- 


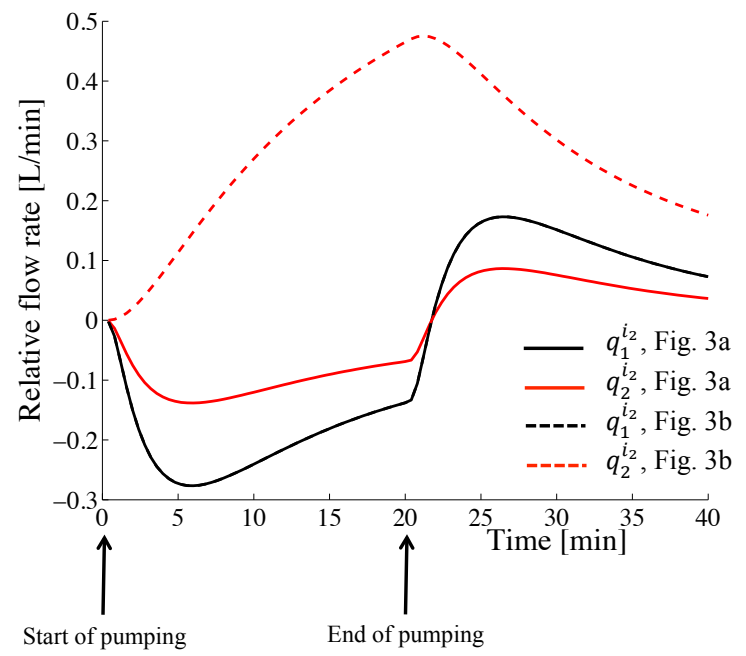

Figure 4: Vertical-flow rate in the observation borehole above Aquifer 1 (black) and above Aquifer 2 (red) for the configurations with connection (solid lines) and without connection (dashed lines) in Figure 3. Note that the vertical flow occurring above Aquifer 1 is identical for the configurations with and without connection, hence the black solid and dashed lines are coincident. 


\subsubsection{Sensitivity analysis}

Because the flow occurring above Aquifer 2 in the observation borehole characterizes the connection configuration, we first demonstrate how our semi-analytical modeling approach can be utilized to efficiently evaluate the overall sensitivity of this particular flow to the hydraulic properties of both aquifers. To this end, we again used the approach to calculate $q_{2}^{i_{2}}(t)$, but this time for a wide range of hydraulic parameter values. Two grid searches were performed. In the first, the logarithms of parameters $T_{1}$ and $T_{2}$ were varied linearly over the range $\left[10^{-7}, 10^{-3}\right] \mathrm{m}^{2} / \mathrm{s}$ while keeping $S_{1}$ and $S_{2}$ fixed at $10^{-5}$. In the second, the logarithms of $S_{1}$ and $S_{2}$ were varied over the same range while keeping $T_{1}$ and $T_{2}$ fixed at $10^{-5} \mathrm{~m}^{2} / \mathrm{s}$. For each parameter combination, vertical-flow-velocity measurements were simulated every 240 seconds, yielding 10 discrete transient data. We hereby denote these data by the vector $\mathcal{Q}_{\mathbf{2}}^{\mathbf{i}_{2}}$, which corresponds to the collection of temporal flow velocities converted into flow rates $(\mathrm{L} / \mathrm{min})$.

Figure 5 shows the distribution of the $\ell^{2}$-norm of $\mathcal{Q}_{\mathbf{2}}^{\mathbf{i}_{2}}\left(\right.$ denoted by $\left.\left\|\mathcal{Q}_{2}^{\mathbf{i}_{2}}\right\|\right)$ obtained from the grid searches for the two connection configurations in Figure 3. In Figure $5 \mathrm{a}$ and b, we see that $\left\|\mathcal{Q}_{\mathbf{2}}^{\mathbf{i}_{2}}\right\|$ is not sensitive to $T_{1}$ when $T_{2}$ is less than $10^{-6} \mathrm{~m}^{2} / \mathrm{s}$, in that it shows no significant variation over all of the considered values of $T_{1}$. This observation corresponds to cases where $\mathcal{Q}_{2}^{i_{2}}$ is limited by the transmissivity of Aquifer 2 and thus does not depend on the transmissivity of Aquifer 1. Figure 5a and $\mathrm{b}$ also show that the highest sensitivity for both configurations (i.e., where we see the most significant variation of $\left.\left\|\mathcal{Q}_{\mathbf{2}}^{\mathbf{i}_{2}}\right\|\right)$ occurs when $T_{1}<T_{2}$. For the configuration with connection (Figure 5a), this corresponds to situations where Aquifer 2 supplies an important part of the water required by the pumping experiment, which 
may imply a strong decrease of the hydraulic head in Aquifer 2 in comparison with Aquifer 1. This in turn leads to a downward flow above Aquifer 2, as seen in Figure 6a where we plot the distribution of the sign of this flow rate during pumping. The amplitude of the downward flow increases for small values of $T_{1}$, where the highest sensitivity of $\left\|\mathcal{Q}_{2}^{\mathbf{i}_{2}}\right\|$ is observed and where the flow is mostly sensitive to $T_{2}$ (Figure $5 \mathrm{a}$ ). For the configuration without connection (Figure 5b), the pumping does not impact directly on the hydraulic head in Aquifer 2. More precisely, it affects the hydraulic head of Aquifer 1, which in turn affects the hydraulic head of Aquifer 2. This implies that small values of $T_{1}$ correspond to situations where the magnitude of $\mathcal{Q}_{2}^{i_{2}}$ is limited by $T_{1}$ and not sensitive to $T_{2}$. Conversely, when considering large values of both $T_{1}$ and $T_{2}$, Aquifer 2 contributes to the pumped flow through the observation borehole and the highest sensitivity of $\left\|\mathcal{Q}_{\mathbf{2}}^{\mathbf{i}_{2}}\right\|$ is observed (Figure 5b).

Concerning the storage coefficients $S_{1}$ and $S_{2}$, Figure $5 \mathrm{c}$ and d show that $\left\|\mathcal{Q}_{\mathbf{2}}^{\mathbf{i}_{2}}\right\|$ is small when the values of these two parameters are large for both connection configurations. This corresponds to cases where the storativities buffer the temporal response of the flow to pumping. For large values of $S_{2},\left\|\mathcal{Q}_{2}^{i_{2}}\right\|$ is also seen to be highly sensitive to $S_{1}$ for both configurations because Aquifer 1 reacts more quickly when its storativity is small, thereby allowing for larger flows from Aquifer 2 to Aquifer 1. For the configuration with connection, a similar high sensitivity to $S_{2}$ is observed for large values of $S_{1}$. As seen in Figure $6 \mathrm{~b}$, this behaviour corresponds to downward flow and is thus specific to this configuration. For the configuration without connection, Figure $5 \mathrm{~d}$ shows that $\left\|\mathcal{Q}_{\mathbf{2}}^{\mathbf{i}_{2}}\right\|$ is poorly sensitive to $S_{2}$ as the behaviour of the flow is mainly determined by $S_{1}$.

The above observations are in agreement with work conducted by Pail- 


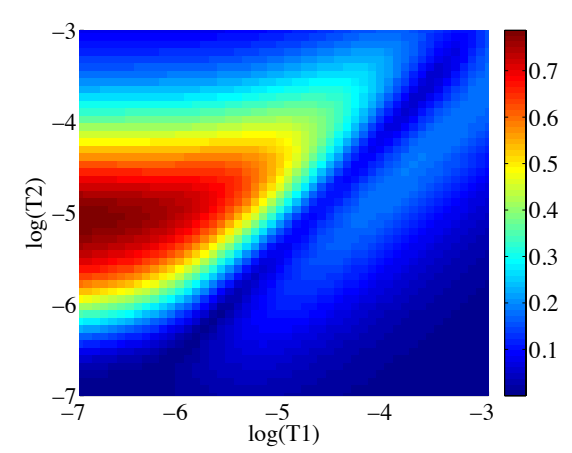

(a) Transmissivity with connection

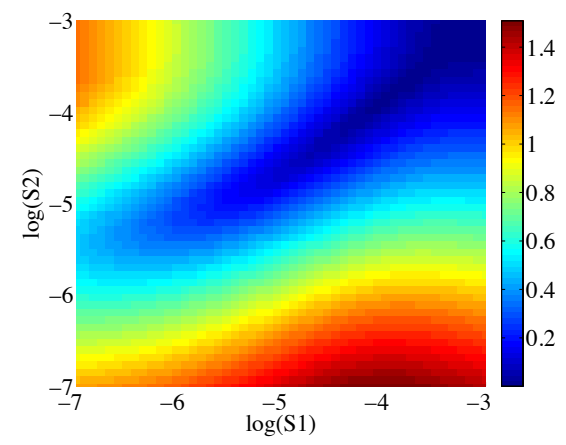

(c) Storativity with connection

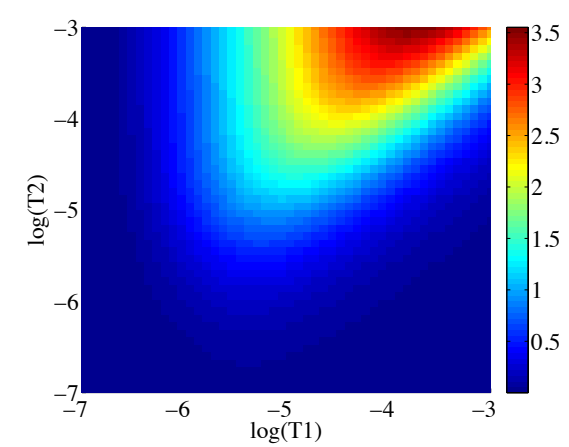

(b) Transmissivity without connection

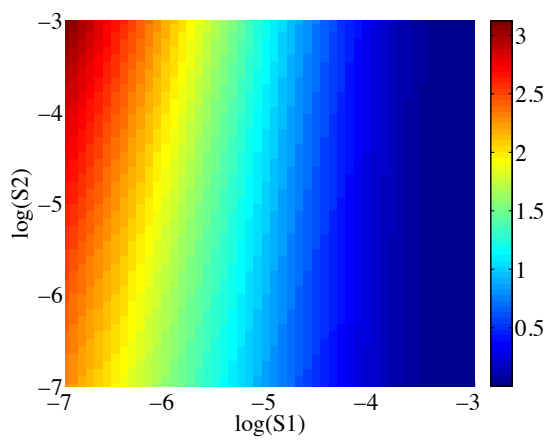

(d) Storativity without connection

Figure 5: Distribution of $\left\|\mathcal{Q}_{\mathbf{2}}^{\mathbf{i}_{2}}\right\|$ for the two configurations in Figure 3 as a function of (a and b) fracture transmissivity values with $S_{1}=S_{2}=10^{-5}$, and (c and d) fracture storativity values with $T_{1}=T_{2}=10^{-5} \mathrm{~m}^{2} / \mathrm{s}$.

let (1998) involving similar simple fracture configurations and investigation of the nature of the vertical-flow velocities in the observation borehole for different hydraulic properties. In that paper, the main conclusions concerning the configuration without connection can be summarized as follows: (i) the flow between Aquifer 2 and Aquifer 1 is always upward; (ii) for $S_{1}=S_{2}=10^{-5}$ and $T_{1}=10^{-5} \mathrm{~m}^{2} / \mathrm{s}$, the magnitude of the flow velocity $q_{2}^{i_{2}}$ increases when $T_{2}$ increases (as seen in Figure $5 \mathrm{~b}$ in our study); and (iii) for 


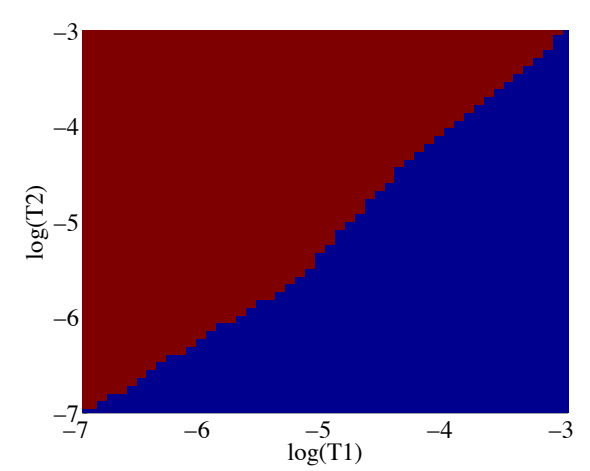

(a) Transmissivity with connection

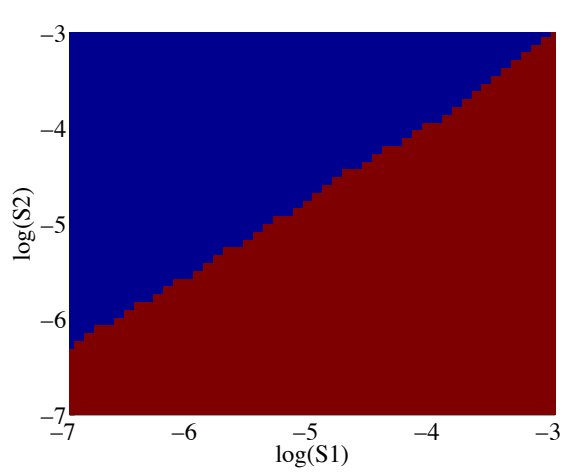

(b) Storativity with connection

Figure 6: Distribution of the sign of the flow rate $\mathcal{Q}_{2}^{i_{2}}$ during pumping for the configuration in Figure 3a and as a function of (a) fracture transmissivity values and (b) fracture storativity values. Values in red are negative (downward flows) whereas those in blue are positive (upward flows).

$T_{1}=T_{2}=10^{-5} \mathrm{~m}^{2} / \mathrm{s}$ and $S_{1}=S_{2}$, increasing the value of the storativities results in a decrease of the magnitude of $q_{2}^{i_{2}}$ (as seen in Figure $5 \mathrm{~d}$ in our study).

\subsubsection{Inversion objective function}

The sensitivity analysis presented above showed that, for the two simple fracture configurations shown in Figure 3, measurements of the flow velocity in the observation borehole contain important information regarding the fracture hydraulic properties and connection configuration. Based on these results, we now demonstrate the use of our modeling approach to examine the objective function corresponding to the least-squares estimation of $T_{1}$, $T_{2}, S_{1}$, and $S_{2}$ from measurements of $q_{1}^{i_{2}}(t)$ and $q_{2}^{i_{2}}(t)$ in the observation borehole. That is, using a grid search over the same parameter ranges as 
before, we now calculate and plot the sum-of-squares misfit

$$
\mathcal{M}=\left\|\left[\begin{array}{c}
\mathcal{Q}_{1}^{\mathbf{i}_{2}}-\mathcal{Q}_{1}^{\mathbf{i}_{2}, \text { ref }} \\
\mathcal{Q}_{2}^{\mathbf{i}_{2}}-\mathcal{Q}_{2}^{\mathbf{i}_{2}, \text { ref }}
\end{array}\right]\right\|^{2}
$$

where $\mathcal{Q}_{\mathbf{1}}^{\mathbf{i}_{2}}$,ref and $\mathcal{Q}_{\mathbf{2}}^{\mathbf{i}_{2}}$,ref are the flow-rate vectors deduced from the transient flow velocities $q_{1}^{i_{2}, r e f}(t)$ and $q_{2}^{i_{2}, r e f}(t)$ corresponding to the "true" or reference set of hydraulic properties, and $\mathcal{Q}_{1}^{\mathbf{i}_{2}}$ and $\mathcal{Q}_{2}^{\mathbf{i}_{2}}$ are the flow rate vectors predicted for specific values of $T_{1}, T_{2}, S_{1}$, and $S_{2}$. The goal of an inversion is to find one or more sets of hydraulic properties that minimize $\mathcal{M}$ to within an acceptable degree.

It is important to note that the analysis performed below should in no way be taken to represent a comprehensive assessment of the cross-borehole flow inverse problem, but rather an example of how our semi-analytical modeling approach can be used to efficiently examine the nature of the inversion objective function to glean information regarding the potential non-uniqueness of the solution and corresponding uncertainty. Indeed, the fracture configurations considered in Figure 3 are far too simple to represent the vast majority of real-world scenarios, and significantly different results should be expected as the number of fractures increases and the geometry becomes more complex. This is explored in further detail in our analysis of field data in Section 3.2.

Figure $7 \mathrm{a}$ and $\mathrm{b}$ show the distribution of the sum-of-squares misfit function in equation (22) for the two connection configurations in Figure 3 assuming "true" parameter values of $T_{1}^{r e f}=T_{2}^{r e f}=10^{-5} \mathrm{~m}^{2} / \mathrm{s}$ and $S_{1}^{r e f}=$ $S_{2}^{r e f}=10^{-5}$. In Figure 7 a the transmissivities are varied while the storativities are held fixed at their true values, whereas in Figure $7 \mathrm{~b}$ the storativities are varied while holding $T_{1}$ and $T_{2}$ at their true values. Note the 
similarity in overall character between Figure 7 and the sensitivity analysis results in Figure 5, which suggests that flow measurements above Aquifer 2 in the observation borehole will have a strong control on the set(s) of hydraulic parameters obtained through inversion. Also note that the shape of the objective function is clearly different between the two configurations. Specifically, the minimum of $\mathcal{M}$ is rather well defined for the configuration with connection, whereas a more complex, elongated form is observed for the configuration without connection. The latter indicates that the existence of a unique and/or easily resolvable minimum is questionable in the unconnected case. For example, the limited change in $\mathcal{M}$ with varying $S_{2}$ over the minimum region in Figure $7 \mathrm{~d}$ implies that it will be difficult to resolve the latter parameter, especially considering the presence of data measurement uncertainties in a realistic scenario.

\subsection{Field study}

To demonstrate the utility of the developed semi-analytical modeling approach in a field context, we now consider the analysis and inversion of cross-borehole flow data acquired in the Melechov Granite at the BohemianMoravian Highland in Czech Republic. These data were previously presented and analyzed by Paillet et al. (2012), which provides a basis for comparing our results with those obtained using their semi-quantitative modeling methodology. Figure 1a shows the flow experiment and overall fracture geometry at the site, the latter of which was inferred from borehole measurements. The radius of the two boreholes is $3.75 \mathrm{~cm}$ and the distance between them is $21 \mathrm{~m}$. For further details concerning the determination of the number of fractures and their position in each borehole, please see Paillet et al. (2012). Connections between fractures viewed at similar depths 


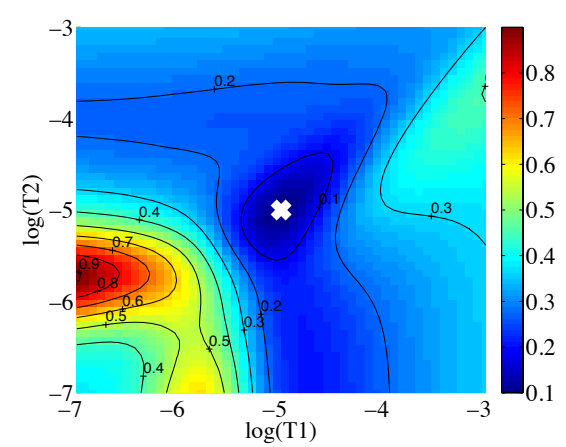

(a) Transmissivity with connection

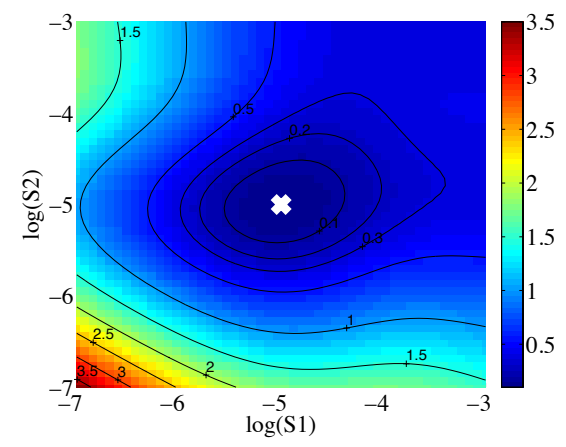

(c) Storativity with connection

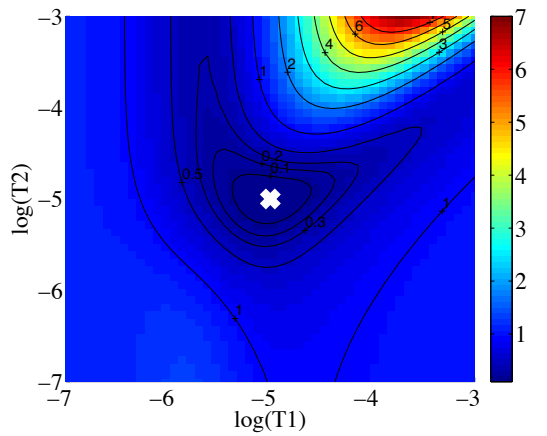

(b) Transmissivity without connection

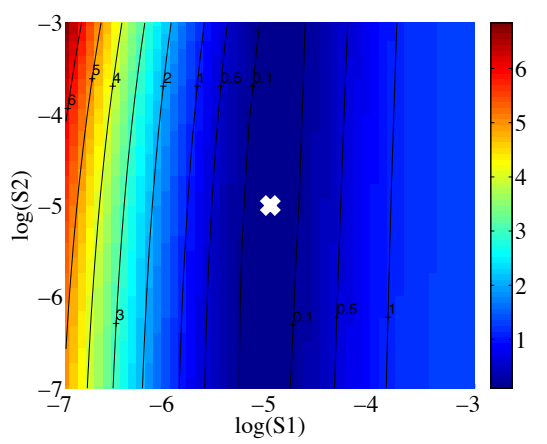

(d) Storativity without connection

Figure 7: Distribution of the sum-of-squares misfit objective function in equation (22) $\left[(\mathrm{L} / \mathrm{min})^{2}\right]$ for the two connection configurations in Figure 3 as a function of (a and b) fracture transmissivity values with $S_{1}=S_{2}=10^{-5}$, and (c and d) fracture storativity values with $T_{1}=T_{2}=10^{-5} \mathrm{~m}^{2} / \mathrm{s}$. The white crosses represent the reference or "true" parameter values and the black lines represent the contours of the objective function.

are shown as initially postulated by Paillet et al. (2012), which leads to the equivalent aquifer representation shown in Figure 1b. During the flow experiment, an extraction rate of $17.8 \mathrm{~L} / \mathrm{min}$ was applied for 20 minutes to the pumped borehole and the flow velocities above each identified fracture in the observation borehole were recorded every minute over this period, as 
well as for an additional 20 minutes thereafter.

In testing of the connection configuration illustrated in Figure $1 \mathrm{~b}$ in the context of their semi-quantitative approach, Paillet et al. (2012) found that, although fractures were observed at similar depths in both the pumped and observation boreholes between $52-56 \mathrm{~m}, 91-96 \mathrm{~m}$, and $136-148 \mathrm{~m}$, it is highly unlikely that the boreholes are actually hydraulically connected at all of these locations. In particular, the fractures between 52-56 m were thought to be very likely connected, the fractures between 136-148 m depth to be very likely not connected, and the connectivity between 91-96 $\mathrm{m}$ to be uncertain. For this reason, in their analysis of the fracture hydraulic properties from the Melechov Granite field data, Paillet et al. (2012) chose to consider two different connection configurations from the one shown in Figure 1b. In the first, only one connection was assumed between the pumped and observation boreholes through Aquifer 2. In the second, both Aquifers 2 and 3 were assumed to provide hydraulic connection between the boreholes. In the present study, we follow along the same lines and perform our inversion for the aquifer hydraulic properties assuming the latter two connection configurations, which we hereby refer to as Model 1 (Figure 8a) and Model 2 (Figure 8b), respectively.

Given the five fractures intersecting the observation borehole, a total of five transmissivities and storativities needed to be estimated from the transient vertical-flow velocity measurements for each connection configuration. To this end, we used our developed modeling approach within a non-linear least-squares inversion framework to minimize the sum-of-squares misfit between the measured data and those predicted using a prescribed set of values for the aquifer hydraulic properties. The optimization was accomplished using the trust-region-reflective algorithm implemented in Matlab (Coleman 


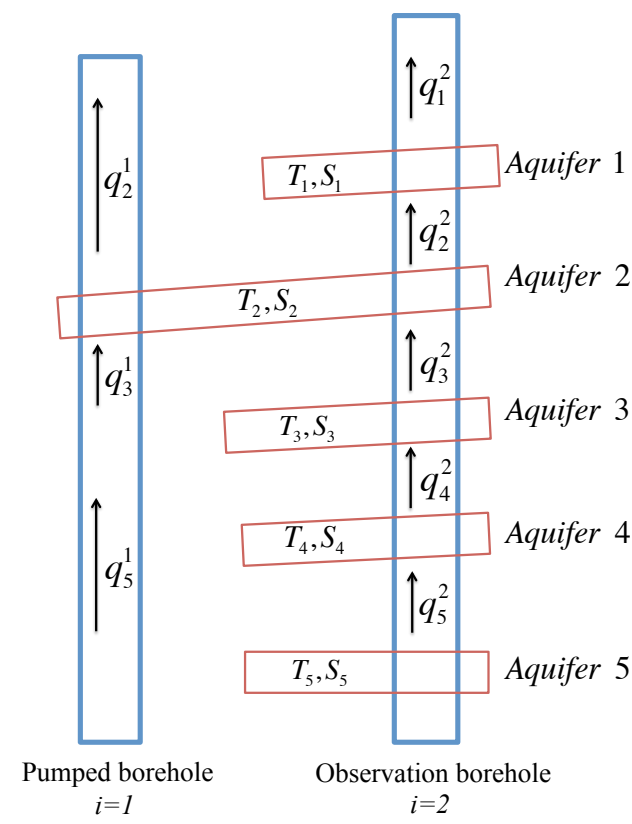

(a) Model 1

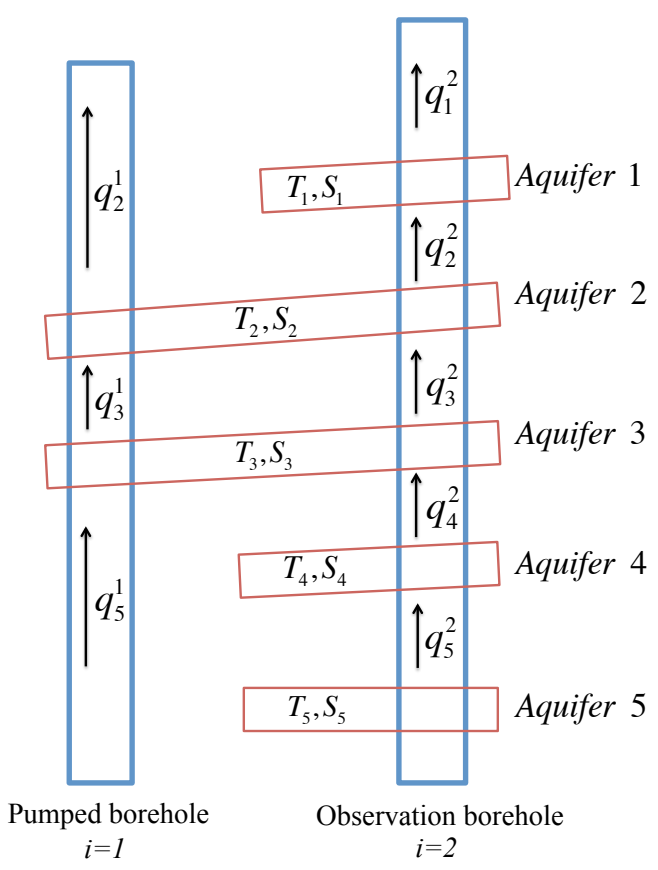

(b) Model 2

Figure 8: Connexion configurations considered in our field study, where the pumped and observation boreholes are connected through (a) Aquifer 2 (Model 1), and (b) Aquifers 2 et 3 (Model 2).

and $L i, 1994,1996)$, which requires a starting point for the inversion and permits the parameter search intervals to be restricted if desired. For each connectivity configuration, 10 inversions were conducted based on different starting points, yielding 10 estimates of the hydraulic properties. The inversion starting points were selected randomly from a uniform distribution for the logarithm of the transmissivity in the range $\left[10^{-7}, 10^{-3}\right] \mathrm{m}^{2} / \mathrm{s}$, and for the logarithm of the storativity in the range $\left[10^{-7}, 10^{-3}\right]$.

Figure 9 shows the distribution of the inversion estimates versus starting points for the transmissivities and storativities for Models 1 and 2. Inver- 
sion results leading to lower sum-of-squares misfits (with objective function values less than $\left.2(\mathrm{~L} / \mathrm{min})^{2}\right)$ are shown in red. We see in the figure that, in general, the highly different inversion starting points lead to similar estimates of the transmissivities, but very different estimates of the storativities. In Figure 9a, for example, the starting points for transmissivity $T_{1}$ for Model 1 leading to the lower objective function values (red circles) vary over two orders of magnitude (from $1.76 \times 10^{-6}$ to $1.81 \times 10^{-4} \mathrm{~m}^{2} / \mathrm{s}$ ), whereas the corresponding inversion estimates vary only from $1.34 \times 10^{-5}$ to $1.71 \times 10^{-5} \mathrm{~m}^{2} / \mathrm{s}$. Considering the other results for $T_{1}$ (green circles), we see a similar behaviour but with convergence of the estimates around a different (higher) value, suggesting the presence of two objective function minima, one of which provides a significantly better fit to the observed data. Similar results are seen for the other transmissivities in Figure 9a, as well as for the transmissivities corresponding to Model 2 in Figure 9b, in that vastly different values for the starting points lead to a relatively narrow clustering of the estimates around a small number of values. With regard to the storativity, on the other hand, we observe in Figure $9 \mathrm{c}$ and $\mathrm{d}$ that the results of the 10 inversions lead to very different parameter estimates that are distributed over many orders of magnitude. That is, there is no clear clustering of storativity values in distinctive regions. For example, in Figure 9c we see that both the starting points and estimates for the storativity $S_{1}$ for Model 1 are distributed over more than two orders of magnitude, even for the points corresponding to the lower misfit values. In agreement with the results of our synthetic investigation, the above findings suggest that crossborehole flow inversions will do a better job of estimating transmissivities than storativities. It appears, as well, that configurations characterized by connections between the pumped and observation boreholes may allow for 
better determination of aquifer hydraulic properties. Indeed, the ranges of variation of the storativity estimates are smaller for Model 2 than Model 1, which was also clearly observed in our synthetic study.

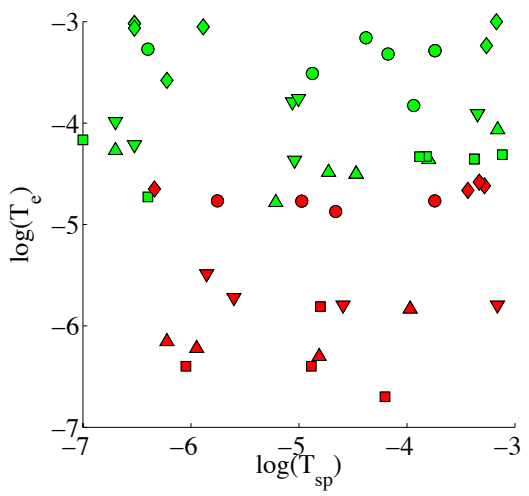

(a) Transmissivity (Model1)

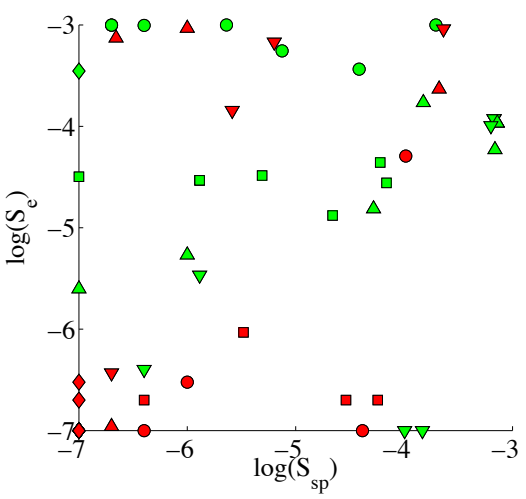

(c) Storativity (Model1)

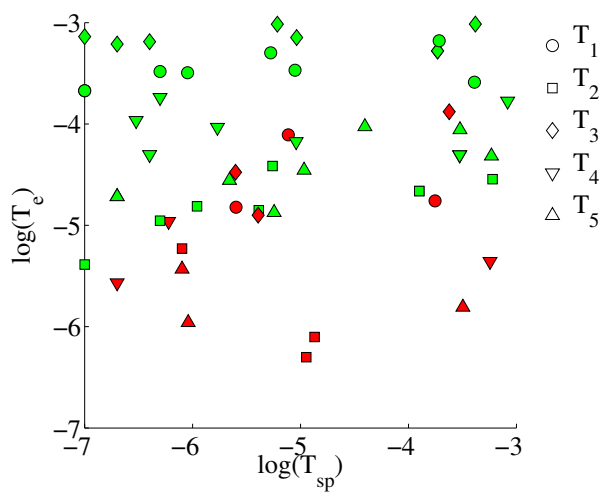

(b) Transmissivity (Model2)

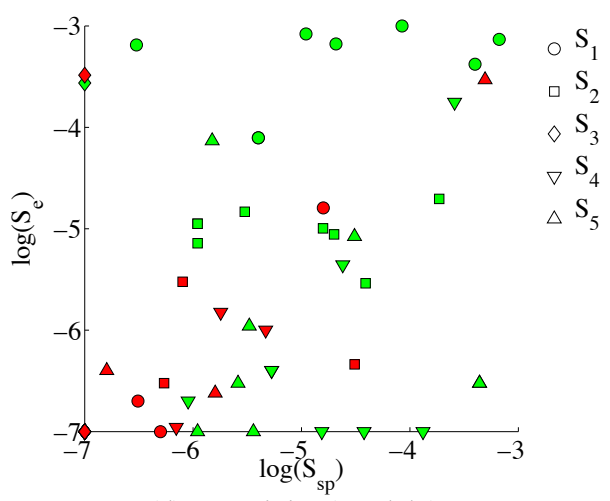

(d) Storativity (Model2)

Figure 9: Distribution of the estimates of ( $\mathrm{a}$ and b) the transmissivity $\left(T_{e}\right)$ and (c and d) the storativity $\left(S_{e}\right)$ obtained through inversion versus the corresponding randomly chosen inversion starting points, $T_{s p}$ and $S_{s p}$. Results for connectivity Model 1 (left column) and Model 2 (right column) are shown. The sum-of-squares misfit objective function corresponding to these estimates ranged from 1.23 to $4.08(\mathrm{~L} / \mathrm{min})^{2}$ for Model 1 and from 0.98 to $4.03(\mathrm{~L} / \mathrm{min})^{2}$ for Model 2. Red symbols indicate parameter estimates resulting in an objective function value of less than $2(\mathrm{~L} / \mathrm{min})^{2}$. 
Finally, we present in Figure 10 the relative vertical flow calculated at different depths in the observation borehole using our semi-analytical approach for connectivity Models 1 and 2, along with the corresponding measured data. For each connection configuration, the two best-fitting sets of predicted data are shown, whose hydraulic properties are given in Table 1. Overall, the best fit between the predicted and observed data is obtained using Model 2 and Parameter Set 2 (thick black curve in Figure 10). Key characteristics of this particular configuration are (i) the assumption of a connection between the pumped and observation boreholes through Aquifer 3 , in contrast with Model 1 which only allows connection through Aquifer 2; and (ii) a large value for the storativity $S_{1}$ and small values for $S_{3}$ and $S_{4}$, in comparison with Model 2, Parameter Set 1. These characteristics allow us to reproduce the sudden change in flow observed between 52-91 m depth immediately after the pumping was stopped (Figure 10b at $t=20 \mathrm{~min}$ ), as well as the negative flow rate in the same depth interval at the beginning of the pumping experiment. In comparison with the study conducted by Paillet et al. (2012), this represents a closer reproduction of the measured data and demonstrates the important impact of fracture storativities. In their investigation, storativity was assumed to be important as the authors suspected that the negative flow rate at the beginning of the pumping experiment resulted from a small storativity in Aquifer 3. However, because they considered a single constant value for the storativity in all fractures, this assumption could not be fully tested. The results presented here indicate that storativity is indeed important and validate the assumption previously made. 

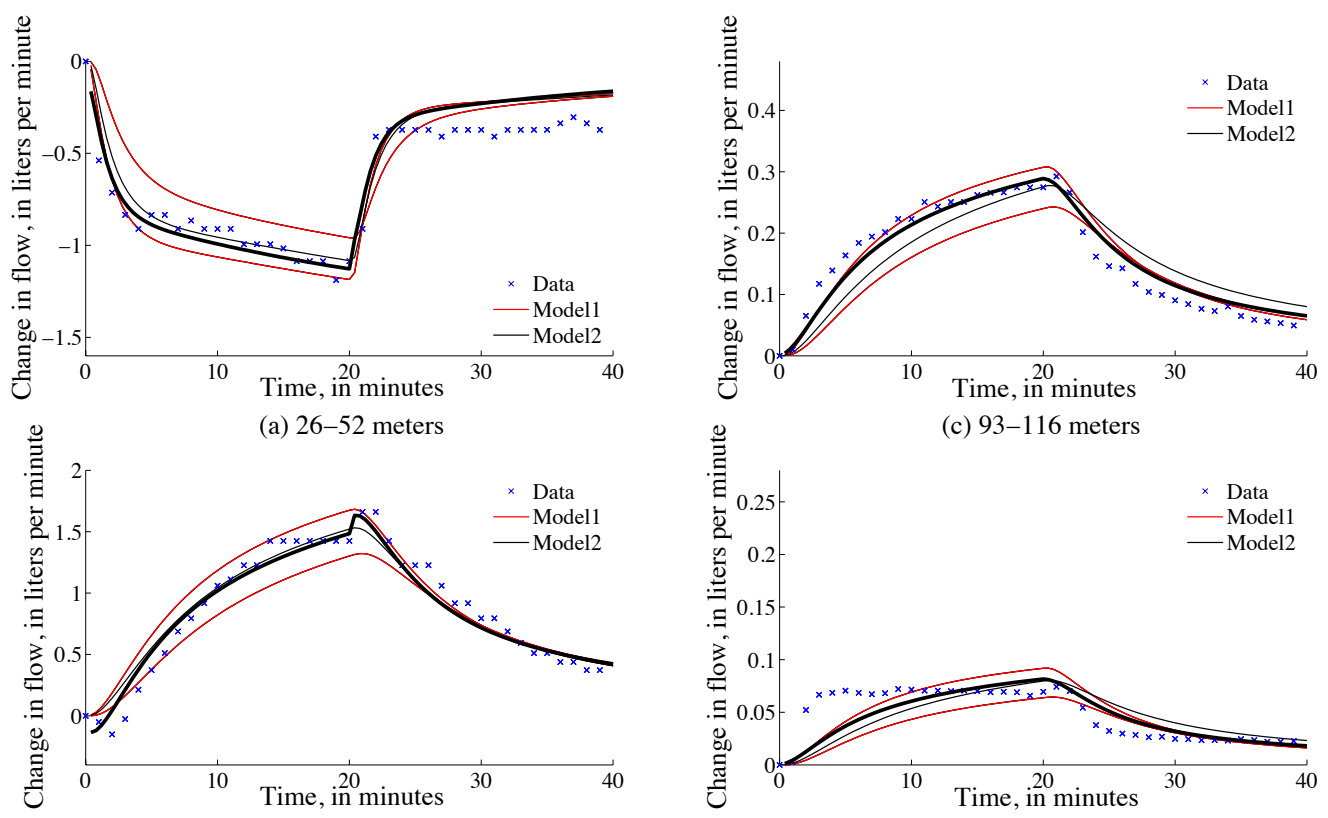

(b) 52-91 meters

(d) 116-139 meters

Figure 10: Relative flow rate in the observation borehole at different depths for the Melechov Granite field study. Shown are the measured data (blue crosses) and the data predicted using our semi-analytical modeling approach assuming connectivity Model 1 (red lines) and Model 2 (black lines). Results for the two best-fitting sets of hydraulic properties (Table 1) are shown. The thick black line indicates the overall best-fitting predicted data, which were obtained assuming connectivity Model 2 and Parameter Set 2.

\section{Conclusions}

We have developed in this paper a new semi-analytical modeling approach

for cross-borehole flow experiments in fractured media, which takes the form of a linear system that must be solved to obtain the vertical-flow velocities above each fracture. The speed and accuracy of this approach make it an ideal tool for sensitivity analysis, where many data must be calculated over a wide range of model parameter configurations. Indeed, simple sensitivity analyses, such as the one conducted in our synthetic study, can provide im- 


\begin{tabular}{|c|c|c|c|c|}
\hline & Model 1, Set 1 & Model 1, Set 2 & Model 2, Set 1 & Model 2, Set 2 \\
\hline$T_{1}$ & $1.7 \times 10^{-5}$ & $1.7 \times 10^{-5}$ & $1.5 \times 10^{-5}$ & $1.7 \times 10^{-5}$ \\
$T_{2}$ & $4 \times 10^{-7}$ & $2 \times 10^{-7}$ & $5 \times 10^{-7}$ & $7.9 \times 10^{-7}$ \\
$T_{3}$ & $2.2 \times 10^{-5}$ & $2.2 \times 10^{-5}$ & $1.3 \times 10^{-5}$ & $3.3 \times 10^{-5}$ \\
$T_{4}$ & $1.6 \times 10^{-6}$ & $1.6 \times 10^{-6}$ & $2.7 \times 10^{-6}$ & $4.4 \times 10^{-6}$ \\
$T_{5}$ & $6 \times 10^{-7}$ & $5 \times 10^{-7}$ & $1.1 \times 10^{-6}$ & $1.6 \times 10^{-6}$ \\
\hline$S_{1}$ & $10^{-7}$ & $10^{-7}$ & $2 \times 10^{-7}$ & $1.6 \times 10^{-5}$ \\
$S_{2}$ & $2 \times 10^{-7}$ & $2 \times 10^{-7}$ & $3 \times 10^{-7}$ & $4.6 \times 10^{-7}$ \\
$S_{3}$ & $2 \times 10^{-7}$ & $3 \times 10^{-7}$ & $3.3 \times 10^{-4}$ & $10^{-7}$ \\
$S_{4}$ & $6.7 \times 10^{-4}$ & $9.1 \times 10^{-4}$ & $10^{-6}$ & $1.1 \times 10^{-7}$ \\
$S_{5}$ & $7.4 \times 10^{-4}$ & $9.3 \times 10^{-4}$ & $4 \times 10^{-7}$ & $2.4 \times 10^{-7}$ \\
\hline $\mathcal{M}$ & 1.2374 & 1.2318 & 1.2961 & 0.9789 \\
\hline
\end{tabular}

Table 1: Two best-fitting sets of transmissivity $\left[\mathrm{m}^{2} / \mathrm{s}\right]$ and storativity [-] estimates, along with the corresponding values for the sum-of-squares misfit $(\mathcal{M})$, for our field example. Results are shown for connectivity Models 1 and 2 presented in Figure 8.

portant insight into parameter identifiability. For example, we found in our case that the highest sensitivity of the borehole flow data is observed when the transmissivity of the upper fracture was smaller than the transmissivity of the lower fracture, as well as that the connection configuration strongly affected the sensitivity to both the transmissivities and the storativities. We also observed in our inverse analysis of the Melechov Granite field data the important role of fracture storativity and how estimating this parameter for each fracture can allow for significantly improved fits to the measured data. As future extensions of this work, further investigation of the cross-borehole flow inverse problem should be considered for more complex fracture configurations, where the "true" connectivity and hydraulic properties of the 
system are known.

It is important to emphasize that our derived semi-analytical formulation is based upon a simplified geological representation, where fractures are modeled as equivalent confined aquifers. Although such a representation has been considered in previous work and clearly allows us to obtain meaningful results, it could be modified with further development to better account for realistic subsurface structure. For example, it may be possible to consider vertical fractures connecting horizontal fractures between the boreholes as localized leakages in our model, where the corresponding hydraulic head would be related to the properties of the vertical fractures. In addition, although the examples presented here focused on two-borehole experiments, our formulation can be easily used to model experiments involving more than one observation well. Finally, in terms of geological structure representation, it may be possible to model the coexistence of fractures and rock and the impact of their related properties with suitable modification. For example, the rock matrix may also provide an important source of storage, resulting in dual-porosity behaviour, which would evidently require coupling of the equations related to the fracture and matrix parts of the system. This could possibly lead to an even better fit of measured field data.

Additional extensions to this work include the development of stochastic inversion strategies for interpreting cross-borehole flow experiments as well for performing uncertainty quantification. The first investigations conducted in this paper demonstrate the potential complexity of the inverse problem, with the possibility of several minima in the objective function for complex fracture networks. Thus, inversion strategies allowing for the possibility of multiple plausible hydraulic parameter and connection configurations are needed, especially if realistic data measurement uncertainties 
are to be considered. Detailed prior information can also help to resolve the non-uniqueness of the inverse problem. In this regard, in addition to information obtained from geophysical logs used for identifying the position of fractures that intersect the boreholes, information from single-hole steadystate tests could be useful for constraining the connectivity and hydraulic property estimates. Although past work has focused on manual calibration of borehole flow models, stochastic methods hold great potential to aid in data analysis.

\section{Appendix: Semi-analytical implementation}

\section{Global and local numbering}

Considering a system of $n$ boreholes where each borehole $i(i=1, \ldots, n)$ intersects $N_{i}$ aquifers, we aim to determine the $N_{\text {flow }}$ borehole vertical-flow velocities in the system where

$$
N_{\text {flow }}=\sum_{i=1}^{n} N_{i} .
$$

For the example in Figure 1b, the system is characterized by $n=2$ boreholes where the pumped $(i=1)$ and observation $(i=2)$ boreholes intersect three $\left(N_{1}=3\right)$ and five $\left(N_{2}=5\right)$ aquifers, respectively. This implies that eight vertical-flow velocities $\left(N_{\text {flow }}=8\right)$ must be defined.

Considering a domain containing a total of $N$ aquifers, we define (i) a global aquifer numbering scheme $(I=1, \ldots, N)$ from the top to the bottom of the domain, and (ii) a local numbering scheme relative to each borehole where the function $f_{i}(I)$ returns the local numbering of aquifer $I$ relative to borehole $i$. Again for the example in Figure 1b, the aquifers are globally numbered from 1 to 5 and locally numbered with the functions $f_{1}(I)$ 
and $f_{2}(I)$ for the pumped and observation boreholes, respectively. As the observation borehole intersects all of the aquifers of the system, the local numbering for this borehole is the same as the global numbering and we have $f_{2}(I)=I$. However, because the pumped borehole intersects only three of the five aquifers, its local numbering is given by $f_{2}(2)=1, f_{2}(3)=2$ and $f_{2}(5)=3$. To obtain the global numbering of an aquifer from its local numbering, we also define the inverse function $g$, where $g_{i}\left[f_{i}(I)\right]=I$.

\section{Linear system construction}

The vertical-flow velocity expressions developed in Section 2.3 .2 can be written as a linear system $\mathbf{A x}=\mathbf{b}$, where unknown vector $\mathbf{x}$ contains the transient velocities discretized in time and matrix $\mathbf{A}$ depends upon the fracture hydraulic properties, connectivity, and experimental geometry. In our construction of this linear system, we consider $\mathbf{x}$ to be comprised of $n$ sub-vectors corresponding to each borehole as follows:

${ }_{64} \quad \mathbf{x}=\left[\begin{array}{c}\mathbf{x}^{1} \\ \vdots \\ \mathrm{x}^{n}\end{array}\right]$.

Each $\mathbf{x}^{i}$ in turn consists of $N_{i}$ sub-vectors representing the different transient flow velocities in borehole $i$. That is,$$
\mathbf{x}^{i}=\left[\begin{array}{c}
\mathbf{x}_{g_{i}(1)}^{i} \\
\vdots \\
\mathbf{x}_{g_{i}\left(N_{i}\right)}^{i}
\end{array}\right]
$$
where vector $\mathbf{x}_{I}^{i}\left(I=g_{i}(1), \ldots, g_{i}\left(N_{i}\right)\right)$ contains the time-discretized relative flow velocity $Q_{I}^{i}$. Considering time to be discretized into $n_{t}$ intervals and 
678

thus expressed as $t_{k}=k \Delta t\left(k=1, . ., n_{t}\right)$ with time step $\Delta t$, we have

$$
\mathbf{x}_{I}^{i}=\left[\begin{array}{c}
Q_{I}^{i}\left(t_{1}\right) \\
\vdots \\
Q_{I}^{i}\left(t_{n_{t}}\right)
\end{array}\right] .
$$

This implies that the total length of vector $\mathbf{x}$ is given by $n_{t} \times N_{\text {flow }}$.

In order to construct matrix $\mathbf{A}$ and vector $\mathbf{b}$, we first note that the convolution product $Q_{K}^{j} *_{t} \mathcal{H}_{I}^{i, j}\left(K=I, I^{\prime}, A_{+}^{j}(I), A_{+}^{j}\left(I^{\prime}\right)\right)$ found in expression (19) can be discretized and expressed at time $t_{k}$ as

$$
\left(Q_{K}^{j} * \mathcal{H}_{I}^{i, j}\right)\left(t_{k}\right)=\sum_{l=1}^{k} \int_{t_{l-1}}^{t_{l}} Q_{K}^{j}\left(t^{\prime}\right) \mathcal{H}_{I}^{j}\left(x_{i}, y_{i}, t_{k}-t^{\prime}\right) \mathrm{d} t^{\prime}
$$

with $t_{0}=0$. This can be approximated as

$$
\left(Q_{K}^{j} * \mathcal{H}_{I}^{i, j}\right)\left(t_{k}\right)=\sum_{l=1}^{k} Q_{K}^{j}\left(t_{l-1 / 2}\right) \mathcal{H}_{I, k, l}^{i, j}
$$

where

$$
Q_{K}^{j}\left(t_{l-1 / 2}\right)=\left[Q_{K}^{j}\left(t_{l-1}\right)+Q_{K}^{j}\left(t_{l}\right)\right] / 2
$$

and

$$
\mathcal{H}_{I, k, l}^{i, j}=\int_{t_{l-1}}^{t_{l}} \mathcal{H}_{I}^{j}\left(x_{i}, y_{i}, t_{k}-t^{\prime}\right) \mathrm{d} t^{\prime}
$$

The previous expression is evaluated as

$$
\mathcal{H}_{I, k, l}^{i, j}=\frac{1}{4 \pi T_{I}} \int_{C_{j}}\left[E_{1}\left(\gamma / t_{k-l+1}\right)-E_{1}\left(\gamma / t_{k-l}\right)\right] \mathrm{d} x^{\prime} \mathrm{d} y^{\prime},
$$

where

$$
E_{1}(\gamma / t)=\int_{0}^{t} \frac{e^{-\gamma / \tau}}{\tau} \mathrm{d} \tau
$$


and

$$
\gamma=\frac{\left(x_{i}-x^{\prime}\right)^{2}+\left(y_{i}-y^{\prime}\right)^{2}}{4 \alpha_{I}}
$$

The integrals over space are then expressed as

$$
\begin{aligned}
& \int_{C_{j}} E_{1}(\gamma / t) \mathrm{d} x^{\prime} \mathrm{d} y^{\prime}= \\
& \int_{0}^{2 \pi} \int_{0}^{r_{j}} r^{\prime} E_{1}\left[\frac{\left(x_{i, j}-r^{\prime} \cos \theta^{\prime}\right)^{2}+\left(y_{i}-r^{\prime} \sin \theta^{\prime}\right)^{2}}{4 \alpha_{I} t}\right] \mathrm{d} r^{\prime} \mathrm{d} \theta^{\prime}
\end{aligned}
$$

where $x_{i, j}=x_{i}-x_{j}+x_{1}$, with $x_{1}$ defined as the origin of the $x$-coordinate.

Note that $y_{i}$ can be set to 0 when considering only two boreholes. Also note that the integrals over space in expression (31) are evaluated numerically when $i \neq j$, and analytically when $i=j$.

The convolution product $\partial_{t} Q_{K}^{j} *_{t} \mathcal{H}_{I}^{i, j}\left(K=I, A_{+}^{j}(I)\right)$ found in expression (21) can be discretized and expressed at time $t_{k}$ as

$$
\left(\partial_{t} Q_{K}^{j} *_{t} \mathcal{H}_{I}^{i, j}\right)\left(t_{k}\right)=\sum_{l=1}^{k} \partial_{t} Q_{K}^{j}\left(t_{l-1 / 2}\right) \mathcal{H}_{I, k, l}^{i, j}
$$

where the time derivative $\partial_{t} Q_{K}^{j}\left(t_{l-1 / 2}\right)$ is approximated as

$$
\partial_{t} Q_{K}^{j}\left(t_{l-1 / 2}\right)=\left[Q_{K}^{j}\left(t_{l}\right)-Q_{K}^{j}\left(t_{l-1}\right)\right] / \Delta t .
$$

Let us now define index $m_{i, I, k}$ related to borehole $i$, aquifer $I$, and discretized time $t_{k}$ as follows:

$$
m_{i, I, k}=\sum_{j=1}^{i-1} N_{j} \times n_{t}+f_{i}(I-1) \times n_{t}+k .
$$

Matrix $\mathbf{A}$ and vector $\mathbf{b}$ can now be defined for $i=1, \ldots, n, I=g_{i}(1), \ldots, g_{i}\left(N_{i}\right)$ and $k=1, \ldots, n_{t}$ as follows: 
705 For $i=1$ (pumped well) and $I=g_{i}(1)$ (the first aquifer intersected by 706 this well):

and

where $\mathcal{Q}$ is the pumping rate, $r_{1}$ is the radius of the pumped borehole, and $t^{*}$ is the pumping time.

$$
b\left(m_{i, I, k}\right)= \begin{cases}\mathcal{Q} /\left(\pi r_{1}^{2}\right), & k \Delta t \leq t^{*} \\ 0, & k \Delta t>t^{*}\end{cases}
$$

${ }_{716} \quad A\left(m_{i, I, k}, m_{j, J, l}\right)= \begin{cases}1, & j=i, J=I, l=k \\ \mathcal{H}_{I, k, l}^{i, j} / \Delta t, & j=1, \ldots, n_{I}, J=I, \\ & l=1, \ldots, k \\ -\mathcal{H}_{I, k, l}^{i, j} / \Delta t, & j=1, \ldots, n_{I}, J=A_{+}^{j}(I), \\ & J \neq N_{j}, l=1, \ldots, k\end{cases}$

718

${ }_{719} \quad A\left(m_{i, I, k}, m_{j, J, l-1}\right)= \begin{cases}-\mathcal{H}_{I, k, l}^{i, j} / \Delta t, & j=1, \ldots, n_{I}, J=I, \\ & l=2, \ldots, k \\ \mathcal{H}_{I, k, l}^{i, j} / \Delta t, & j=1, \ldots, n_{I}, J=A_{+}^{j}(I), \\ & J \neq N_{j}, l=2, \ldots, k\end{cases}$

721 and

$$
b\left(m_{i, I, k}\right)=0 .
$$


$724 \quad$ Finally, for $i=1, \ldots, n$ and $I=g_{i}(2), \ldots, g_{i}\left(N_{i}\right)$, expression (19) leads to:

$725 \quad A\left(m_{i, I, k}, m_{j, J, l}\right)= \begin{cases}1, & j=i, J=I, l=k \\ \beta_{I}^{i} \mathcal{H}_{I, k, l}^{i, j} / 2, & j=1, \ldots, n_{I}, J=I, \\ & l=1, \ldots, k \\ -\beta_{I}^{i} \mathcal{H}_{I, k, l}^{i, j} / 2, & j=1, \ldots, n_{I}, J=A_{+}^{j}(I), \\ & J \neq N_{j}, l=1, \ldots, k \\ -\beta_{I^{i}}^{i} \mathcal{H}_{I^{\prime}, k, l}^{i, j} / 2, & j=1, \ldots, n_{I^{\prime}}, J=I^{\prime}, \\ & J \neq N_{j}, l=1, \ldots, k \\ \beta_{I}^{i} \mathcal{H}_{I^{\prime}, k, l}^{i, j} / 2, & j=1, \ldots, n_{I^{\prime}}, J=A_{+}^{j}\left(I^{\prime}\right), \\ & J \neq N_{j}, l=1, \ldots, k\end{cases}$

727

${ }_{728} \quad A\left(m_{i, I, k}, m_{j, J, l-1}\right)= \begin{cases}\beta_{I}^{i} \mathcal{H}_{I, k, l}^{i, j} / 2 & j=1, \ldots, n_{I}, J=I, \\ & l=2, \ldots, k \\ -\beta_{I}^{i} \mathcal{H}_{I, k, l}^{i, j} / 2 & j=1, \ldots, n_{I}, J=A_{+}^{j}(I), \\ & J \neq N_{j}, l=2, \ldots, k \\ -\beta_{I^{i}}^{i} \mathcal{H}_{I^{\prime}, k, l}^{i, j} / 2 & j=1, \ldots, n_{I^{\prime}}, J=I^{\prime}, \\ & J \neq N_{j}, l=2, \ldots, k \\ \beta_{I}^{i} \mathcal{H}_{I^{\prime}, k, l}^{i, j} / 2 & j=1, \ldots, n_{I^{\prime}}, J=A_{+}^{j}\left(I^{\prime}\right), \\ & J \neq N_{j}, l=2, \ldots, k\end{cases}$

730 and

${ }_{732}^{731}$

$$
b\left(m_{i, I, k}\right)=0 .
$$




\section{Acknowledgments}

This work was supported in part by the U.S. Geological Survey Toxic Substances Hydrology Program. Any use of trade, firm, or product names is for descriptive purposes only and does not imply endorsement by the U.S. Government. We thank Frederick L. Paillet and John H. Williams for helpful discussions and for providing the field data considered in this study, along with five anonymous reviewers for their constructive and helpful comments.

\section{References}

Avci, C. (1994), Evaluation of flow leakage through abandoned wells and boreholes, Water Resources Research, 30, 2565-2578, doi: 10.1029/94WR00952.

Bear, J. (1979), Hydraulics of Groundwater, McGraw-Hill series in water resources and environmental engineering, McGraw-Hill International Book Co.

Carneiro, J. F. (2009), Numerical simulations on the influence of matrix diffusion to carbon sequestration in double porosity fissured aquifers, International Journal of Greenhouse Gas Control, 3(4), 431-443, doi: 10.1016/j.ijggc.2009.02.006.

Carslaw, H., and J. Jaeger (1986), Conduction of Heat in Solids, Oxford science publications, Clarendon Press.

Chen, C., and J. Jiao (1999), Numerical simulation of pumping tests in multilayer wells with non-Darcian flow in the wellbore, Ground Water, 37(3), 465-474, doi:10.1111/j.1745-6584.1999.tb01126.x. 
Cihan, A., Q. Zhou, and J. T. Birkholzer (2011), Analytical solutions for pressure perturbation and fluid leakage through aquitards and wells in multilayered-aquifer systems, Water Resources Research, 47, W10,504, doi:10.1029/2011WR010721.

Coleman, T., and Y. Li (1994), On the convergence of interior-reflective newton methods for nonlinear minimization subject to bounds, Mathematical Programming, 67(1-3), 189-224, doi:10.1007/BF01582221.

Coleman, T., and Y. Li (1996), An interior trust region approach for nonlinear minimization subject to bounds, SIAM Journal on Optimization, 6(2), 418-445, doi:10.1137/0806023.

Day-Lewis, F. D., C. D. Johnson, F. L. Paillet, and K. J. Halford (2011), A computer program for Flow-Log Analysis of Single Holes (FLASH), Ground Water, 49(6), 926-931, doi:10.1111/j.1745-6584.2011.00798.x.

Dershowitz, W., and I. Miller (1995), Dual porosity fracture flow and transport, Geophysical Research Letters, 22(11), 1441-1444, doi: 10.1029/95GL01099.

Gautam, P., and K. Mohanty (2004), Matrix-fracture transfer through countercurrent imbibition in presence of fracture fluid flow, Transport in Porous Media, 55(3), 309-337, doi: 10.1023/B:TIPM.0000013326.95597.10.

Hearst, J., P. Nelson, and F. Paillet (2000), Well Logging for Physical Properties: A Handbook for Geophysicists, Geologists, and Engineer, John Wiley and Sons Inc. New York, 492 pp., ISBN 0-471-96305-4. 
Keys, W. S., and L. M. MacCary (1971), Application of borehole geophysics to water-resources investigations, U.S. Geological Survey Techniques of Water-Resources Investigations, book 2, chap. E1, p. 8-12, 19, 22, 30-36, 64-66.

Klepikova, M. V., T. Le Borgne, O. Bour, K. Gallagher, R. Hochreutener, and N. Lavenant (2014), Passive temperature tomography experiments to characterize transmissivity and connectivity of preferential flow paths in fractured media, Journal of Hydrology, 512(0), 549-562, doi: 10.1016/j.jhydrol.2014.03.018.

Klepikova, M. V., T. Le Borgne, O. Bour, and J.-R. de Dreuzy (2013), Inverse modeling of flow tomography experiments in fractured media, Water Resources Research, 49(11), 7255-7265, doi:10.1002/2013WR013722.

Kolditz, O., and C. Clauser (1998), Numerical simulation of flow and heat transfer in fractured crystalline rocks: Application to the hot dry rock site in rosemanowes (u.k.), Geothermics, 27(1), 1-23, doi: http://dx.doi.org/10.1016/S0375-6505(97)00021-7.

Lapcevic, P. A., K. S. Novakowski, and F. L. Paillet (1993), Analysis of flow in an observation well intersecting a single fracture, Journal of Hydrology, 151 (2-4), 229-239, doi:10.1016/0022-1694(93)90237-4.

Le Borgne, T., F. Paillet, O. Bour, and J. Caudal (2006), Cross-borehole flowmeter tests for transient heads in heterogeneous aquifers, Ground Water, 44 (3), 444-452, doi:10.1111/j.1745-6584.2005.00150.x.

Leaf, A. T., D. J. Hart, and J. M. Bahr (2012), Active thermal tracer tests 
for improved hydrostratigraphic characterization, Ground Water, 50(5), 726-735, doi:10.1111/j.1745-6584.2012.00913.x.

Nordbotten, J. M., M. A. Celia, and S. Bachu (2004), Analytical solutions for leakage rates through abandoned wells, Water Resources Research, 40(4), W04,204, doi:10.1029/2003WR002997.

Paillet, F. (2012), A mass-balance code for the quantitative interpretation of fluid column profiles in ground-water studies, Computers $\&$ Geosciences, $45(0), 221-228$, doi:10.1016/j.cageo.2011.11.016.

Paillet, F. L. (1998), Flow modeling and permeability estimation using borehole flow logs in heterogeneous fractured formations, Water Resources Research, 34(5), 997-1010, doi:10.1029/98WR00268.

Paillet, F. L., J. H. Williams, J. Urik, J. Lukes, M. Kobr, and S. Mares (2012), Cross-borehole flow analysis to characterize fracture connections in the Melechov Granite, Bohemian-Moravian Highland, Czech Republic, Hydrogeology Journal, 20(1), 143-154, doi:10.1007/s10040-011-0787-1.

Pehme, P., B. Parker, J. Cherry, J. Molson, and J. Greenhouse (2013), Enhanced detection of hydraulically active fractures by temperature profiling in lined heated bedrock boreholes, Journal of Hydrology, 484(0), 1-15, doi:10.1016/j.jhydrol.2012.12.048.

Rotter, B. E., D. A. Barry, J. I. Gerhard, and J. S. Small (2008), Modeling $\mathrm{U}(\mathrm{VI})$ biomineralization in single- and dual- porosity porous media, Water Resources Research, 44(8), W08,437, doi:10.1029/2007WR006301.

Williams, J., and F. Paillet (2002), Using flowmeter pulse tests to define hy- 
825 draulic connections in the subsurface: a fractured shale example, Journal 826 of Hydrology, 265(1-4), 100-117, doi:10.1016/S0022-1694(02)00092-6. 